\title{
The Economic Burden of HIV and AIDS on Fish Production in Turkana County, Kenya
}

\author{
Jeremia Lomari Apalia, Urbanus Mutuku Kioko* \\ School of Economics, University of Nairobi, Nairobi, Kenya \\ Email address: \\ apalialomari@gmail.com (J. L. Apalia), urbanusmutukukioko@gmail.com (U. M. Kioko) \\ ${ }^{*}$ Corresponding author
}

\section{To cite this article:}

Jeremia Lomari Apalia, Urbanus Mutuku Kioko. The Economic Burden of HIV and AIDS on Fish Production in Turkana County, Kenya. International Journal of Health Economics and Policy. Vol. 4, No. 3, 2019, pp. 67-72. doi: 10.11648/j.hep.20190403.11

Received: March 25, 2019; Accepted: July 12, 2019; Published: July 26, 2019

\begin{abstract}
Estimating and determining the economic burden of Human Immunodeficiency Virus (HIV) and Acquired Immuno Deficiency Syndrome (AIDS) on productivity is critical especially on the primary livelihood of any fishing community. If these communities are adversely affected by HIV and AIDS, the aggregate supply of fish may be adversely affected in real absolute numbers. It is in this reference that this study sought not only to identify factors affecting fish productivity but also to investigate the economic burden of HIV and AIDS in Lake Turkana County. To achieve this objective, the study collected primary data through structured questionnaires in the sampled areas of Namukuse and Kalokol sublocations in Turkana County. Since HIV and AIDS is endogenous in the production model, the study applied Two Stage Least Square (2SLS) regression modeling technique to estimate the economic burden of HIV and AIDS on fish production. The findings showed that both HIV and AIDS, and the number of fishing nets significantly influence fish productivity in Lake Turkana while other diseases and age were also found to be significant determinants of fish production. Based on the study results, the study recommends that the national government and county government accelerate HIV/AIDS education among the finishing community and also fast track implementation of appropriate prevention measures such as use early diagnosis and treatment and use of PrEP given that the finishing community can be classified among the high-risk population groups.
\end{abstract}

Keywords: Economic Burden, Fish Production, HIV and AIDS, Turkana County, 2SLS

\section{Background Information}

According to the World Health Organization (WHO), health is defined as a state of complete physical, social and mental well-being and not merely the absence of disease or infirmity. Productivity is an expression of how efficiently and effectively goods and services (i.e. goods and services demanded by users) are being produced [1]. Poor health can destabilize households' livelihoods through loss of labour and earnings. Households practicing farming in the long run would suffer from knowledge loss due to morbidity and mortality and will be forced to either reduce the area of land under farming or the variety of crops they grow.

According to Canning health is an important form of human capital that can enhance worker's productivity by increasing their physical capacities as well as their mental capacities [2]. Further Kwadwo Asenso-Okyere showed that production is affected in a greater way upon the death of an adult household member [3]. This is because his or her contribution to agricultural production and income is lost permanently. Other studies link high HIV prevalence to food insecurity because the pandemic affects the ability of a household to produce food due to illness or death as a result of the scourge [4-5].

In Turkana Cunty, finishing is one of the main sources of livelihood and about $12 \%$ of the total county population depends on it for survival [6]. Fishing is more labour intensive and requires a healthy labour force. In Kenya for instance, the sub-sector earns fishermen approximately Ksh 7 billion, while fish exports earn the country about Ksh five billion in foreign exchange annually [7].

However, output from the fishing sub-sector has been declining over time in Lake Turkana. For instance, data from the county fisheries office show average annual fish production from 2001 to 2007 was 4,843 tons. This is far 
below the estimated potential of about 30,000 tons annually [8-9]. The low and declining production could be linked to ill health caused by a high prevalence of HIV and AIDS among the fisher folk, over-fishing, under exploitation of fisheries and low production from aquaculture [10].

Although several studies exist on the cost burden of HIV and AIDS on agricultural production, evidence of the economic burden of the disease on fish farming in Turkan County is not available. This study fills this gap by estimating the economic burden of HIV and AIDS on fish production among communities living along Lake Turkana in the Northern part of Kenya.

\section{Reviewed Literature}

HIV and AIDS has been shown to affect both directly and indirectly the productivity of individuals or workers through its effect on the social, human and physical capital [11]. It affects the human capital since it is highly prevalent among the economically active and working populations, thus destroying the accumulation of human stock for future investments. A socio-economic descriptive report on the impact of AIDS, highlighted that the disease affects agriculture in many ways, which include work absenteeism caused by HIV related illnesses and loss of labour from AIDS related deaths which lead to a reduction in land under cultivation [12]. This further causes a decline in yields and changes in the cropping systems leading to reduced food production. It also noted that the death of crucial family members also causes the loss of knowledge on the traditional know how of farming methods.

Other studies found that fisher folk in Kenya have a higher HIV infection than all the other groups considered like injectable drug users (IDUs) and the truck drivers (13]. Others have found that fishermen are among the most at-risk population than all other perceived groups like truck drivers and farmers [14-15]. Mwakalobo in Rungwe district, Tanzania found that HIV infected or affected households spend less on food than households without HIV, since most of their incomes are spent on treatment [16].

Another study using longitudinal regression in modelling the impact of HIV/AIDS on labour productivity in tea plucking estates workers in western Kenya found out that HIV positive workers plucked less tea in the 18 months preceding their AIDS related termination hence earning less than their HIV negative counterparts [17]. A similar study in Nigeria found that HIV and AIDS had adverse impacts on household productivity, income, savings and capital formation [12].

From the foregoing, it is evident that most researchers have employed and utilized many different approaches. Several studies have used panel data while others used cross sectional data. Most studies done on HIV and AIDS have focused in modelling its macroeconomic effects on the economy and the GDP [13, 17]. Most of them used simulations of both the "AIDS scenario and No AIDS scenarios while others used Computable General Equilibrium (CGE) models [11, 19].

\section{Methodology}

\subsection{The Empirical Model}

Since the study investigates the economic burden of HIV and AIDS on fish production output, we adopt a simple functional form of a production function expressed as follows:

$$
\mathrm{Q}=\mathrm{f}(\mathrm{K}, \mathrm{H}, \mathrm{D}, \mathrm{X}, \varepsilon)
$$

Where:

Q- Value of fish output in Kenya Shillings

$\mathrm{K}$ - Vector of quantities of physical inputs such as fishing gear (Nets and boats owned by a fishing Household)

$\mathrm{H}-\mathrm{HIV}$ and AIDS incidence

D- Other disease incidence

$\mathrm{X}$ - Vector of household characteristics such as sex and age of the fishers

$\varepsilon$ - Idiosyncratic disturbance term

The functional form of the model to measure the effect of the other vector of variables on fish output is specified as follows;

$$
\mathrm{Q}=\alpha+\beta_{1} \mathrm{~K}+\beta_{2} \mathrm{H}+\beta_{3} \mathrm{D}+\beta_{4} \mathrm{X}+\varepsilon
$$

Where;

Q- Value of fish output in Kenya Shillings

$\alpha-$ an intercept showing that level of fish production not influenced by HIV prevalence and other explanatory variables

$\beta_{1}$ - An intercept showing the effect of other physical factors (inputs) that affect fish production

$\beta_{2}$ - The coefficient of interest that measures the effect of HIV and AIDS on fish output

$\beta_{3^{-}}$- The coefficient measuring the effect of other diseases on fish production

$\beta_{4^{-}}$The coefficient measuring the effect of other household/individual characteristics on overall fish production

The literature indicates that HIV and AIDS negatively affect productivity and therefore the coefficient on $\beta_{2}$ is expected to be negative [20]. This implies that fish production declines if a fishing member of a household is affected/infected by HIV and AIDS. Therefore, taking HIV and AIDS as a discrete variable, i.e. the value of 1 if a household member of a fishing household is affected/infected by HIV and AIDS and 0 otherwise, the conditional production functional form becomes;

$$
\mathrm{Q}^{\Lambda}=\alpha+\beta_{1}{ }^{\Lambda} \mathrm{K}_{\mathrm{i}}+\beta_{2}{ }^{\Lambda} \mathrm{H}+\beta_{3}{ }^{\Lambda} \mathrm{D}+\beta_{4} \mathrm{X}_{\mathrm{j}}
$$

Where:

$\mathrm{i}=1,2\left(\mathrm{~K}_{1}=\right.$ Quantity of fishing nets by a fishing Household; $\mathrm{K}_{2}=$ Boats/rafters used by the fishing household member).

$\mathrm{j}=1,2\left(\mathrm{X}_{1}=\right.$ age of the fishing household member (adult or young: Adult $=1 ; 0$ otherwise); $\mathrm{X}_{2}=$ the sex of the fishing household member (Male or female: If male $=1 ; 0$ otherwise).

The estimated coefficient ${ }^{1}$ of HIV and AIDS is used to 
determine the burden of the disease on fish production. The specific equation to determine the economic burden of HIV and AIDS on fish production is therefore expressed as follows:

$$
\Psi=[\exp (\hat{\theta})-1] * 100
$$

Where $\Psi$ is the economic burden of HIV and AIDS on fish production and therefore represents the percentage negative change in production due to HIV and AIDS. The parameter $\hat{\theta}$ is negative.

Table 1 presents the definition, measurement and expected a priori effect of HIV and AIDS on fish production.

Table 1. Definition and Measurement of Variables.

\begin{tabular}{|c|c|c|c|c|}
\hline & Variable & Description/Measurement & $\begin{array}{l}\text { A priori } \\
\text { (Predicted) Effect }\end{array}$ & $\begin{array}{l}\text { Data } \\
\text { Sources }\end{array}$ \\
\hline 1. & HIV and AIDS incidence & $\begin{array}{l}\text { Proportion of sampled population affected or infected with HIV } \\
\text { and AIDS, taking the value of } 1 \text { if affected/infected; } 0 \\
\text { otherwise) }\end{array}$ & Negative & Primary data \\
\hline \multirow{2}{*}{2.} & Vector variables $K_{1}$ (Fishing nets) & $\begin{array}{l}\text { The number of fishing nets owned and used by the household } \\
\text { for fishing. }\end{array}$ & Positive & Primary data \\
\hline & $\begin{array}{l}\text { Vector variable } \mathrm{K}_{2} \text { (boats and/or rafters } \\
\text { used by the household }(\mathrm{HH})\end{array}$ & $\begin{array}{l}\text { Binary variable. We take } 1 \text { for } \mathrm{HH} \text { using boat to fish, } 0 \\
\text { otherwise. }\end{array}$ & Positive & Primary data \\
\hline 3. & $\begin{array}{l}\text { Other diseases, (D) i.e. Malaria, } \\
\text { Pneumonia etc. }\end{array}$ & $\begin{array}{l}\text { Proportion of the sampled population suffering from malaria or } \\
\text { pneumonia, taking the value } 1 \text { if infected; } 0 \text { otherwise }\end{array}$ & Negative & Primary data \\
\hline \multirow{2}{*}{4.} & $\begin{array}{l}\text { Household/Individual characteristics: } \\
\text { Age of the fishing member of a } \mathrm{HH}\left(\mathrm{X}_{1}\right)\end{array}$ & $\begin{array}{l}\text { Adult or young. } \\
\text { If Adult }=1 ; 0 \text { otherwise }\end{array}$ & Positive & Primary data \\
\hline & Sex of a fishing member of a $\mathrm{HH}\left(\mathrm{X}_{2}\right)$ & $\begin{array}{l}\text { Male or Female } \\
\text { If Male }=1 ; 0 \text { otherwise }\end{array}$ & Positive & Primary data \\
\hline
\end{tabular}

\subsection{Estimation Issues}

Given that HIV and AIDS is endogenous to fish production, the study used instrumental variable approach to estimate the economic burden of the disease on fish production. The instrument for HIV and AIDS was distance to the nearest health as an instrumenting variable. Distance to the nearest health facility is related to HIV and AIDS because individual can seek advice on the prevention and treatment of HIV and AIDS but unrelated to fishing. Therefore, this is an appropriate instrument for HIV and AIDS. Distance to the nearest health facility is positively associated with being affected or infected with HIV and AIDS. The Instrumented first stage regression (HIV and AIDS) shows the factors that affect the likelihood of being affected/infected with HIV and AIDS in Turkana County. The study further established that fishing boats and sex of the fishermen contributed positively to the likelihood of being affected or infected with HIV and AIDS by $31.3 \%$ and 5.5\% holding other factors constant.

\subsection{Estimation Method}

The study employed 2SLS regression modelling techniques to estimate the economic burden of HIV and AIDS on fish production. It is expected that the HIV and AIDS variable which is the main independent variable will be endogenous within the model. This is demonstrated by the fact that HIV and AIDS at least from the literature is expected to have a negative effect on the overall fish production output while at same time, fish production output, whether reduced or increased, would influence the amount of income among the fishermen, which has an overall effect on the HIV and AIDS prevalence. This endogeneity condition of the independent variable of interest therefore becomes a problem within the model because it creates inconsistency and bias on the estimates such that;

$$
\operatorname{Cov}(H, \varepsilon) \neq 0
$$

To address this problem, we introduced instruments (variables) related to HIV and AIDS variable but not with the fish output, denoted by W. The appropriate instrument is the distance to the nearest health facility. This is because persons infected or affected by HIV and AIDS will tend to live near health facilities to easily access treatment.

$$
\begin{aligned}
& \operatorname{Cov}(W, \varepsilon)=0 \\
& \operatorname{Cov}(W, H) \neq 0
\end{aligned}
$$

where;

$\mathrm{W}$ is the distance to the nearest health facility, $\mathrm{H}$ is the variable of interest, and $\boldsymbol{\varepsilon}$ is the error term Because of endogeneity problem, we used the 2SLS method of regression to estimate the predicted values of the estimates which are consistent and not biased. We then run the first regression against the $\mathrm{H}$ variable and get the predicted $\mathrm{H}^{\wedge}$. The predicted values of the $\mathrm{H}$ variable are then used in the second stage of the regression such that the equation becomes;

$$
\mathrm{Q}^{\wedge}={ }_{\alpha}+\beta_{1}{ }^{\wedge} \mathrm{K}_{\mathrm{i}}+\beta_{2}{ }^{\wedge} \mathrm{H}^{\wedge}+\beta_{3}{ }^{\wedge} \mathrm{D}+\beta_{4} \mathrm{X}_{\mathrm{j}}+\varepsilon_{\mathrm{i}}^{\wedge}
$$

\subsection{Data Type and Sources}

The study used cross sectional primary data collected through face to face interviews with respondents in the sampled areas of Namukuse and Kalokol sub-locations. The data on HIV and AIDS affected or infected households (specifically fishing households) was obtained from the health facilities in the sampled areas. The structured questionnaire was the main research instrument for the collection of primary data from the households and the facilities. 


\subsection{Sampling and Sample Size}

Kalokol and Namukuse sub-locations were first identified through clustering of areas/beaches along the Lake Turkana conducting heavy fishing and purely depending on the fishing livelihood. According to the Kenya Population and Housing Census (2009), Kalokol sub-location has a population of 11,480 with 2,311 households while Namukuse sub-location that has both Namukuse and Longech villages has a population of 6,282 with 1,031 households. Then random sampling method was used to identify a total of 90 fishing households for the study comprising of 30 households from each target area while balancing for both the affected/ infected and the non-affected/non-infected households.

\section{Results}

\subsection{Descriptive Statistics}

Table 2 shows the characteristics of the factors included in the estimation of the economic burden of HIV and AIDS on fish production in Turkana. The findings show that average fish output per household was equivalent to Kshs 4873.67 per month with the least household's fish output valued at Kshs 200 and the highest household getting Kshs 30,000. The mean age of the respondents was 49 years with a variation of 20 years implying that majority of the fishermen were adults although the youngest was 16 years old and the oldest fisherman was 89 years. With respect to the number of fishing nets, the results revealed that some fishermen owned 60 fishing nets while others owned none implying that they either borrowed or hired fishing net(s) from other fisher men. Close to $86 \%$ of the respondents were found to use boats in their fishing activities while $14 \%$ used other means.

About $89 \%$ indicated that they had suffered from diseases like pneumonia, malaria among other conditions. Further, out of the total respondents surveyed, $95.6 \%$ of the fishermen indicated that they were aware of HIV and AIDS with a small variation of $20.7 \%$. As expected, $90 \%$ of the respondents were male while females involved in fishing accounted for only $10 \%$. On average, most fishermen travelled 1.79 Kilometres to reach to the lake with a standard deviation of 1.3 kilometres.

Table 2. Descriptive Statistics.

\begin{tabular}{|c|c|c|c|c|c|}
\hline Variable & No. of observation & Mean & Std. Dev. & Min & Max \\
\hline Output & 90 & 4873.6 & 6130.0 & 200 & 30000 \\
\hline Age & 90 & 49.2 & 20.2 & 16 & 89 \\
\hline Age (binary) & 90 & 0.96 & 0.18 & 0 & 1 \\
\hline Sex & 90 & 0.9 & 0.30 & 0 & 1 \\
\hline Fishing nets & 90 & 14.8 & 14.80 & 0 & 60 \\
\hline Fishing Boats & 90 & 0.8 & 0.35 & 0 & 1 \\
\hline Other diseases & 90 & 0.8 & 0.31 & 0 & 1 \\
\hline Distance & 90 & 1.79 & 1.34 & 0.1 & 6 \\
\hline
\end{tabular}

\subsection{Empirical Results}

Table 3 presents regression results. Based on the Instrumental Variables (2SLS) Regression results in Table 3, HIV and AIDS, other diseases, age and fishing nets were found to be statistically significant determinants of fish production in Turkana. Also, fishing boats and sex of the fishermen were shown to be statistically insignificant determinants of fish productivity. The coefficient on HIV and AIDS was -82174.1 and statistically significant at 5\% level implying that a unit increase in the incidence of HIV and AIDS reduces fish output by Ksh. 82,174. This is the measure of the economic burden of HIV and AIDS on fish production. Similarly, the coefficient on other diseases, in this case malaria and pneumonia, was $-12,480.68$ and significant at $10 \%$ level implying that a unit increase in the prevalence of these diseases reduce fish production by Ksh. $12,480.68$.

Table 3. Effect of HIV and AIDS on fish production in Lake Turkana.

\begin{tabular}{lllllll}
\hline Output & Coefficients & Std. Err. & Z & P>z & [95\% Conf. & Interval] \\
\hline HIV/AIDS & $-82174.1^{* *}$ & 34967.702 & -2.35 & 0.024 & -538056.9 & 373708.7 \\
Other Diseases & $-12480.68^{*}$ & 6972.4469 & -1.79 & 0.071 & -96680.57 & 71719.2 \\
Age & $258.9746^{* * *}$ & 78.00439 & 3.32 & 0.001 & -1340.356 & 1858.305 \\
Fishing Nets & $35.90586^{* *}$ & 13.75703 & 2.61 & 0.019 & -656.858 & 728.6697 \\
Fishing Boats & 26602.53 & 73518.91 & 0.36 & 0.717 & -117491.9 & 170696.9 \\
Sex & 6311.351 & 18296.95 & 0.34 & 0.730 & -29550.01 & 42172.71 \\
Constant & 35419.99 & 15136.75 & 2.34 & 0.030 & -165978.6 & 236818.6 \\
Instrumental Variables (2SLS) Regression & & & & & \\
Number of Observations $=90$ & & & & & \\
Wald chi2(6)=0.64 & & & & & \\
Prob $>$ chi2 = 0.0172 & & & & & \\
Partial R squared $=0.23$ & & & & & \\
Test for exclusion of instruments $\mathrm{F}(1,83)=8.125011^{*}$ & & & & & \\
\hline
\end{tabular}

*Significant at $10 \%, * *$ significant at $5 \%$ and $* * *$ significant at $1 \%$. 
The coefficient on age was 258.97 and significant at $1 \%$ level. This implied that age of the fisherman, increases fish production by Ksh. 258.97 at ceteris paribus. Finally, the number of fishing nets owned by the fishermen was shown to increase the total fish output at $5 \%$ significant level by Kshs 35.91 .

\subsection{Discussion of the Results}

The estimation results showed that HIV and AIDS reduces fish production by huge amounts. For instance, an increase in the prevalence of HIV among the fishing community by $1 \%$ reduces production by Kshs $82,174.1$ while reduction by other diseases reduces fish production by Ksh. 12,480.68. This clearly shows that the economic burden inflicted by HIV and AIDS on fish production is much higher compared to that of other conditions combined. If the condition is not reversed, then the fishing community will most likely lose their livelihood because of inability to engage in fishing.

The findings of this study are similar to those by Were and Nafula who showed that HIV and AIDS negatively impacts on the Kenyan economic growth [11]. The authors showed that HIV and AIDS affects economic growth through its effect on labour productivity and loss of earnings, that productivity of workers is affected through effects on the social, human and physical capital. They suggested that higher costs related to HIV and AIDS infection reduces physical capital accumulation since most of the resources are channeled towards treatment and control of the disease.

The study further established that age of the fishermen increased the total fish output. From the literature, age is considered as the proxy for experience. The results imply that more experienced fishermen were more likely to report a higher fish production compared to less experienced fishermen. An extra year in the sector leads to more output. The study concurs with the study conducted in Kenya [21] which established the effect of HIV and AIDS on commercial agricultural sector.

The study also found a positive relationship between fish production and the number of fishing nets. The significant relationship was expected as owning more fishing nets implies extra catch and thus output.

\section{Conclusion and Policy Recommendations}

\subsection{Conclusions of the Study Findings}

In developing economies, fishing communities account for $95 \%$ of the world's fisher folk community and supply more than half of the total world fish production. This implies that if these fishing communities are adversely affected by HIV and AIDS, then the aggregate world supply of fish may be affected in real absolute numbers. Fishing is one of the main sources of livelihood in Turkana County and about $12 \%$ of the total county population depends on it for survival. Since the fishing sub-sector just like the other sectors of crop farming and livestock farming is indicated as labour intensive requiring a healthy labour force, this study sought to explore the economic burden of HIV and AIDS on fish production in Turkana County.

From the study results, HIV and AIDS, and other diseases (malaria and pneumonia) were found to negatively influence fish production in Lake Turkana. Fishing nets and Age were found to positively contribute to productivity.

\subsection{Policy Recommendations}

HIV and AIDS is shown to be one of the main health challenges affecting the fish production in Turkana County. Given the available evidence, there is need for proper policy decisions such as intensive HIV and AIDS education programme and sensitization of individuals involved in fish production to establish their status and seek early treatment. This will reduce the economic burden on the disease on fish production. Mitigation efforts will reduce mortality of crucial family members which causes the loss of knowledge on the traditional knowledge of finishing.

Since the fishing communities were shown to have more than $90 \%$ HIV and AIDS prevalence rate, fishermen are thus among the most at-risk population than all other perceived groups. The prevalence rates among the finishing communities in Turkana County is often five to ten times higher than the national average.

To mitigate against the effect of other diseases on fish production, it will be imperative to increase the distribution of bed nets among the fishing communities which experience high prevalence of malaria. Further, the County Government of Turkana County need to subsidize fishing nets to make them affordable to the fishing population. The government and the relevant stakeholders have a role to design the appropriate policy through the relevant ministry or department to protect the interests of these marginalized communities and thus empower them economically through provision of these and other complementary fishing materials.

\section{References}

[1] http://www.who.int/governance/eb/who_constitution_en.pdf

[2] Canning, D. E. (2005). Health and Economic Growth: Reconciling the Micro and Macro Evidence. Harvard School of Public Health.

[3] Kwadwo Asenso-Okyere (2011). Interactions Between Health and Farm-Labour Productivity. Washington, DC: International Food Policy Research Institute.

[4] O'Donnell M (2004). Food security, livelihoods and HIV/AIDS: A guide to the Linkage, Measurement and Programming implications. Save the Children, UK.

[5] Gillespie SL, Haddad L \& Jackson R (2001). HIV/AIDS, food and nutrition security: impacts and actions. 28th Session of the ACC/SCN Symposium on Nutrition and HIV/AIDS. Geneva: ACC/SCN. 
[6] Jeppe $\mathrm{K}$ et al., (2010). Fisheries in the drylands of SubSaharan Africa" fish come with the rains". Building resilience for fisheries-dependent livelihoods to enhance food security and nutrition in the drylands. Food and Agriculture Organization of the united nations, Rome, 2016.

[7] Maina, J G, (2010). Fish Production in Kenya: Opportunities, Challenges and way Forward.

[8] Kallqvist, T., L. Lien \& D. Liti, (1988). Lake Turkana, Limnological study 1985-1988. Oslo, Norwegian Institute for Water research. p. 98.

[9] Hopson A. J (ed.) (1982). Lake Turkana: A Report on the Findings of the Lake Turkana Project, 1972-75, Volumes 1-6, University of Stirling (funded by the Government of Kenya and the Ministry of Overseas Development, Overseas Development Administration, London).

[10] http://farmbizafrica.com, why fish production is declining in Kenya

[11] Were, M., \& Nafula, N. (2003). An assessment of the impact of HIV/AIDS on economic growth. The case of Kenya. Cecifo Working Paper, 1034.

[12] Iya, I. B., Purokayo, S. G., and Yusuf, G. (2012). The Effects of HIV/AIDS Scourge on Production and Income among Rural Households in Adamawa State of Nigeria. Global Journal of Health Science, Vol. 4, No. 1. www.ccsenet.org/gjhs
[13] Kissling, E. H. (2005). Fisherfolk are among groups most at risk of HIV: cross-country analysis of prevalence and numbers infected. AIDS. Vol. No. pp 1939-1946.

[14] FAO (2006): "The State of World Fisheries and Aquaculture."

[15] Gordon, A. (2005). HIV/AIDS in the fisheries sector in Africa. Cairo, Egypt: World Fish Center.

[16] Mwakalobo, A. B. (2007). Implications of HIV/AIDS for Rural Livelihoods in Tanzania: The Example of Rungwe District. African Studies Review, VOL. No. pp 51-73.

[17] Mathew P. F, Sydney R, William B. M, Monique W, Margaret B, Ginamarie F, and Jonathan L, S (2004). The impact of HIV/AIDS on labour productivity in Kenya. Journal of Tropical Medicine and International Health. volume 9 no 3 pp 318-324 March 2004.

[18] Cuddington, J. T. (1993). Modeling the Macroeconomic Effects of AIDS, with an Application to Tanzania. The World Bank Economic Review, Vol. pp 173-189.

[19] Arndt, C., and Lewis, J. D. (2000). The Macro Implications of HIV/AIDS in South Africa: A Preliminary Assessment.

[20] Kioko, U. (2013). Economic Burden of Malaria on Subsistence crop production in Kenya. International Journal of Education and Research, Vol. 1 No. 4 April 2013.

[21] Rugalema, G. (1999). HIV/AIDS and the Commercial Agricultural Sector of Kenya. FAO. 